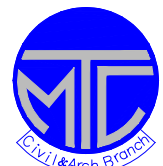

ICCAE

Military Technical College

Kobry Elkobbah,

Cairo, Egypt 7th International Conference

On Civil \& Architecture

Engineering

\title{
PREDICTION OF COMPRESSIVE STRENGTH OF GLASS FIBER REINFORCED GYPSUM WALL PANELS
}

\author{
SREENIVASA R. L. , DEVDAS MENON ${ }^{\dagger}$, AND MEHER PRASAD A. ${ }^{\ddagger}$
}

\begin{abstract}
Glass fiber reinforced gypsum (GFRG) walls are relatively new building materials that have been developed in the last decade in Australia and are now being used in many other countries as structural walls. The GFRG wall panels are hollow panels made of phosphogypsum (an industrial by-product) and reinforced with glass fibers. These panels (120 mm thick) have rectangular cavities. With the increasing use of
\end{abstract}

\footnotetext{
*Ph. D Research Scholar, Civil Eng. Dept., Indian Institute of Technology-Madras, Chennai-600036, India, E-mail: sreenivasarl@rediffmail.com

${ }^{\dagger}$ Professor, Civil Eng. Dept., Indian Institute of Technology-Madras, Chennai-600036, India, E-mail: dmenon@iitm.ac.in

‡ Professor, Civil Eng. Dept., Indian Institute of Technology-Madras, Chennai-600036, India, E-mail: prasadam@iitm.ac.in
} 
GFRG wall panels, structural design guidelines, based on proper studies have become necessary. In this paper, a method is proposed to predict the compressive strength of GFRG wall panels, including slenderness effects and non-linear stressstrain behavior of the material. These results also been validated with experimental results obtained from tests conducted and limited number of experimental results available in literature. It is seen that the proposed method gives more accurate results than the existing methods.

\section{KEY WORDS}

Composite structures, Gypsum walls, Gypsum, Critical load, Compression members, and Fibers.

\section{NOMENCLATURE}

The following symbols are used in this paper;

$A=$ Cross sectional area.

$\mathrm{B}=$ Breadth of the wall.

$E=$ Young's modulus.

$\mathrm{E}_{\mathrm{t}}=$ Tangent modulus.

$I_{\min }=$ Minimum moment of inertia.

$I_{x x}=$ Moment of inertia about centroidal horizontal axis-xx.

$I_{y y}=$ Moment of inertia about centroidal vertical axis-yy.

$K=$ Effective length factor.

$L=$ Actual height of wall panel.

$P_{c}=$ Crushing load.

$P_{c r}=$ Critical load.

$\left(P_{c r}\right)_{\text {Euler }}=$ Euler critical load.

$\left(P_{c r}\right)_{\text {Tangent }}=$ Tangent modulus theory critical load.

$P_{e u}=$ Experimental ultimate load in compression.

$P_{u}=$ Theoretical ultimate load in compression.

$P_{t}=$ Tangent modulus load.

$r=$ Least radius of gyration.

$T=$ Thickness of wall panel.

$\sigma_{c r}=$ Critical stress in compression.

$\sigma_{c}=$ Crushing stress of blocks in compression.

$\sigma_{u}=$ Theoretical ultimate stress in compression.

$\sigma_{e u}=$ Experimental ultimate stress in compression.

\section{INTRODUCTION}

Glass fiber reinforced gypsum (GFRG) wall panels are made of composite material comprising calcinated gypsum $(96.5 \%)$ reinforced with glass fibers. Presently, these 
panels are manufactured with a size of $2.85 \mathrm{~m}$ in height, $12 \mathrm{~m}$ in length and $120 \mathrm{~mm}$ in thickness. The wall panels have rectangular cavities throughout the height. A typical cross section of the GFRG panel is shown in Fig. 1. The front and rear faces of the panel, called flanges, are $13 \mathrm{~mm}$ thick, and are interconnected by means of vertical ribs, $20 \mathrm{~mm}$ thick, spaced $250 \mathrm{~mm}$ apart. The gypsum used for manufacture is phosphogypsum, which is a waste product of the chemical industry. The glass fibers used as reinforcement are 13 micron rovings, 300 to $350 \mathrm{~mm}$ long, and are located in the middle of the panel faces and their connecting ribs. The total glass fiber content per metre square of the panel is $8 \mathrm{~N}$.

The GFRG walls and their associated building products have been in use in the Australian building industry since 1990. This technology has since been introduced to Malaysia in 1997, to China in 2001, and very recently to India. It is suitable for mass scale housing, and has the merits of being economical and ecofriendly, suitable for durable and rapid construction of housing and buildings.

In view of the extensive increasing usage of this material, there is a need to establish its structural characteristics in order to facilitate reliable structural design. At present, there is limited experimental data available ([4],[5] and [10]), based on which design recommendations have been proposed in Australia [6]. However, these design recommendations are semi empirical in nature, and need to be refined on the basis of further experimental and theoretical studies.

The present study is a contribution in this direction. It is based on experimental studies carried out at Indian Institute of Technology-Madras (IITM) on GFRG full scale panels and blocks to ascertain the basic constitutive relationship of the material. This relationship is then used in a theoretical study to estimate the strength of the GFRG wall panel subjected to axial compression.

\section{STRESS-STRAIN CURVE OF GFRG IN AXIAL COMPRESSION}

In order to obtain the stress-strain curve of GFRG, under axial compression two GFRG blocks of size $300 \times 300 \times 120 \mathrm{~mm}$ were subjected to axial compression in a force controlled compression testing machine at IITM. Pellets were fixed at a gauge length of $100 \mathrm{~mm}$ in both vertical and horizontal directions. A P-fender gauge of least count $0.001 \mathrm{~mm}$ was used to measure the deformations of the block. At every $10 \mathrm{kN}$ increment of loads, the deformations were measured and the loading continued till failure of the specimen.

The stress strain curve is plotted by best curve fitting using average values of the two tests. The stress-strain graph, shown in Fig.2, is non-linear throughout. The initial tangent modulus is found to be $16 \mathrm{GPa}$. The values of Tangent modulus at different stress levels (at intervals of $0.5 \mathrm{MPa}$ ) obtained from this plot are summarized in Table 1.

\section{AXIAL COMPRESSION TESTS ON UNFILLED GFRG WALL PANELS}

The GFRG wall panels used in building construction are likely to be subjected to combination of axial load, horizontal shear, in-plane and out-of-plane bending due to gravity and lateral (wind and earthquake) loads. The scope of the present study is limited to unfilled GFRG wall panels subject to concentric axial compression. This is the starting point for further studies related to combined load effects. 
Experimental tests have been carried out on unfilled GFRG wall panels of full height $(2.85 \mathrm{~m})$ at IITM, Structural Engineering Research Centre (SERC), Chennai, India [4] and University of Adelaide, South Australia [5]. One full scale GFRG wall panel $1.02 \mathrm{~m}$ length, $2.85 \mathrm{~m}$ high with both ends pinned is conducted. The results are summarized in Table 2. The ultimate load is obtained as $135.0 \mathrm{kN}$. The panel failed locally at the bottom support. In the tests carried out at SERC, the panels were $2.0 \mathrm{~m}$ wide, with the top and bottom ends of the panel pinned. All the three panels tested failed by buckling. The results are also summarized in Table 2. The average ultimate load was obtained as $143.6 \mathrm{kN}$. In the tests carried out at University of Adelaide, the panels were $1.02 \mathrm{~m}$ wide, and the tests were carried out with the base fixed and the top pinned. All the three panels tested failed by buckling. The results are summarized in Table 3. The average ultimate load was obtained as $152.0 \mathrm{kN}$.

Compression tests on small GFRG blocks of size $300 \times 300 \times 120 \mathrm{~mm}$ were also carried out. All the blocks failed by crushing and the results are summarized in Table 4. It may be noted that whereas the compressive strength of the GFRG material is $7.31 \mathrm{MPa}$, the actual stress realized in the full wall panel tests was, on the average, 4.0 MPa for both ends pinned condition and 4.23 MPa for one end fixed and other end pinned condition, due to slenderness effects.

The purpose of the present study is to enable a prediction of load carrying capacity in axial compression of unfilled GFRG wall panels of any size and boundary conditions, based on first principles and validation of the test results reported in Tables 2 and 3.

\section{PREDICTION OF CRITICAL LOAD OF GFRG WALL PANEL BY TRADITIONAL METHODS}

The traditional methods for finding critical load in column include Euler's theory, Rankine's theory, Reduced modulus theory and Tangent modulus theory. Among these, Euler's theory and the Tangent modulus theory are expected to give the extreme bounds of the critical load. Accordingly, these are examined for their applicability to unfilled GFRG wall panels.

\subsection{Euler's Theory}

The Euler's equation to find the critical load $\mathrm{P}_{\mathrm{cr}}$ of a compression member of effective length $\mathrm{KL}$ for a linearly elastic material is given by:

$$
\left(P_{c r}\right)_{\text {Euler }}=\frac{\pi^{2} E I}{(K L)^{2}}
$$

where $\mathrm{I}$ is moment of inertia, $\mathrm{K}$ is effective length factor, $\mathrm{L}$ is actual length and $\mathrm{E}$ is Youngs modulus may be taken as the initial tangent modulus.

\subsection{Tangent Modulus Theory}


The Tangent modulus equation to find the critical load of a compression member is given by:

$$
\left(P_{c r}\right)_{\text {Tangent }}=\frac{\pi^{2} E_{t} I}{(K L)^{2}}
$$

where $E_{t}$ is the Tangent modulus corresponding to critical stress in compression $\sigma_{c r}$ $=P_{c r} / A(A$ is the cross sectional area).

The above two methods are applied to the GFRG wall panel with cross sectional dimension, $1.02 \mathrm{~m}$ wide (ie. with four cells), $0.12 \mathrm{~m}$ thick and $2.85 \mathrm{~m}$ high. This cross section is shown in Fig. $1 \mathrm{~b}$ and the recommended effective length factors $\mathrm{K}$ are summarized in Table 5. The results are tabulated in Table 6 for panels with (i) both ends pinned and (ii) one end fixed and the other pinned. The critical stress obtained from Euler's theory, Tangent modulus theory, experimental result and experimental results from literature are plotted in Fig. 3 for various slenderness ratios, with the critical stress normalized with respect to the crushing strength of GFRG blocks.

The results shows that both methods tend to grossly over-estimate the critical load capacity, with the Tangent modulus theory performing better. Fig. 3 shows that the disparities between Euler's theory and Tangent modulus theory are predominant at low values of slenderness ratio. The seven experimental results deal with wall panel slenderness ratios of 47.5 and 59.4, corresponding to which both methods seem to predict that the failure is expected to occur by material crushing and not by buckling. This has been disproved by the experiments.

\section{PROPOSED METHOD}

The comparison of the experimental results with the existing theories seem to suggest that the behavior of the GFRG material is different from other civil engineering materials such as steel and Aluminum, for which the existing theories are more appropriate. Unlike these materials, GFRG has a non-linear stress-strain curve throughout. The slenderness ratios of wall panels in practice is in between 30 and 60, and the effective length to thickness ratio is in the range 12 to 24 . For such walls, the effects due to imperfections (accidental eccentricity of load, lack of straightness, etc) need to be also considered.

It is seen that the traditional Rankine's theory is an empirical formulation which addresses the effects of imperfections in real columns. The failure load of the column is expressed in terms of the crushing load capacity of the short column and the Euler's buckling load of the column. In order to also account for the nonlinearity of the GFRG material, it is proposed to modify Rankine's formula by replacing the Euler's buckling load with the Tangent modulus load as follows:

$$
\frac{1}{P_{u}}=\frac{1}{P_{c}}+\frac{1}{P_{t}}
$$


where $P_{u}$ is the Ultimate load, $P_{c}$ is Crushing load and $P_{t}$ is tangent modulus load (given by Eq. (2))

$$
P_{c}=\sigma_{c} A
$$

Where $\sigma_{\mathrm{c}}$ is crushing stress.

$$
\begin{aligned}
& \text { Substituting for } \mathrm{P}_{\mathrm{c}} \text { and } \mathrm{P}_{\mathrm{t}} \text { in Eq. (3) } \\
& \qquad \frac{1}{P_{u}}=\frac{1}{\sigma_{c} A}+\frac{1}{\left(\frac{\pi^{2} E_{t} I}{(K L)^{2}}\right)}
\end{aligned}
$$

By substituting $\quad \mathrm{I}=\mathrm{A} \mathrm{r}^{2}$ and simplifying ( $\mathrm{r}$ is least radius of gyration),

$$
P_{u}=\frac{\sigma_{c} A}{1+\left(\frac{\sigma_{c}}{\pi^{2} E_{t}}\right)(K L / r)^{2}}
$$

The application of equation (5) to the panels used in the experimental studies, show results of failure load that correspond closely to the experimental results, as indicated in Table 6 and Fig. 3. The proposed method, which is a modification of Rankine's method including the concept of Tangent modulus, is found to predict the ultimate loads of unfilled GFRG panels better than the existing methods.

\section{RECOMMENDED PROCEDURE FOR ULTIMATE LOAD ESTIMATION}

The proposed procedure for estimating ultimate load $P_{u}$ of the unfilled GFRG panel under axial compression is an iterative procedure. Using a simple algorithm, the solution of ultimate stress $\left(P_{u} / A\right)$ has been obtained for various values of slenderness ratio $(\mathrm{KL} / \mathrm{r})$, and the results plotted in Fig. 4, which can serve as a useful design chart, applicable for any given set of geometrical properties (cross sectional area $A$, effective length $K L$, and radius of gyration $r$ ). For a given value of $K L / r$, the value of ultimate stress $\sigma_{u}=P_{u} / A$ is obtained from Fig. 4. It is easy to refine this value to obtain a more accurate estimate by applying equation (5).

\section{CONCLUSIONS}

This paper presents a method to evaluate the ultimate loads of GFRG unfilled hollow wall panels subjected to axial loads. The proposed method is a modification of Rankine's theory, utilizing the non-linear stress-strain behavior of GFRG material in the estimation of inelastic buckling load. This procedure is found to be more accurate than any of the traditional methods for estimating the ultimate axial compressive strength of GFRG wall panels. The test result and limited experimental tests reported in the literature have confirmed the suitability of the present approach. 


\section{REFERENCES}

[1] Aravindan, P. K., Prasad, A. M., and Menon, D. . Gypcrete / Rapidwall buildings engineering design manual, a design manual for GFRG walls prepared by Structural engineering division, Civil engineering department, Indian Institute of TechnologyMadras, India, (2003).

[2] Bureau of Indian Standards (BIS), Plain and reinforced concrete code of practice, IS 456 , a Indian code of practice, (2000).

[3] Chajes, A.. Principles of structural Stability theory, Prentice-Hall, Inc. publishers, Englewood cliffs, New Jersey, (1974).

[4] Structural Engineering Research Center, Investigation on the behaviour of Gypcrete panels and blocks under static loading, a report prepared for M/S Gypcrete Building India (P) Ltd., Chennai, India, (2002).

[5] Dare Sutton Clarke Engineers, A 2002 report in to the physical testing and the development of design guidelines for the structural application of Rapidwall in building construction, Adelaide, South Australia, (2002).

[6] Dare Sutton Clarke Engineers, Rapidwall engineering design guidelines, Adelaide, South Australia, (2002).

[7] Indian Institute of Technology-Madras, Material properties and assessment of Gypcrete building panels, a report prepared for M/S Gypcrete Building India (P) Ltd., Chennai, India, (2002).

[8] Kripanarayanan, K. M., and Fintel, M. Analysis and design of slender tilt up R.C. wall panels, ACI Str. J., vol. 71, No1, pp 20-28, (1974).

[9] Timoshenko, S. P., and Gere, J. M. Theory of elastic stability, Second edition, McGraw-Hill publishers, Kogakusha, LTD. (1961).

[10] Wu YF., and Dare MP., Axial and shear behaviour of glass fibre reinforced gypsum wall panels: Tests, ASCE J. Composites for construction, vol. 8, No 6, pp 569-578, (2004).

[11] Wu YF. The effect of longitudinal reinforcement on the cyclic shear behaviour of glass fibre reinforced gypsum wall panels: Tests., J. Engineering structures, vol. 26, No 11, pp 1633-1646, (2004). 
(a)

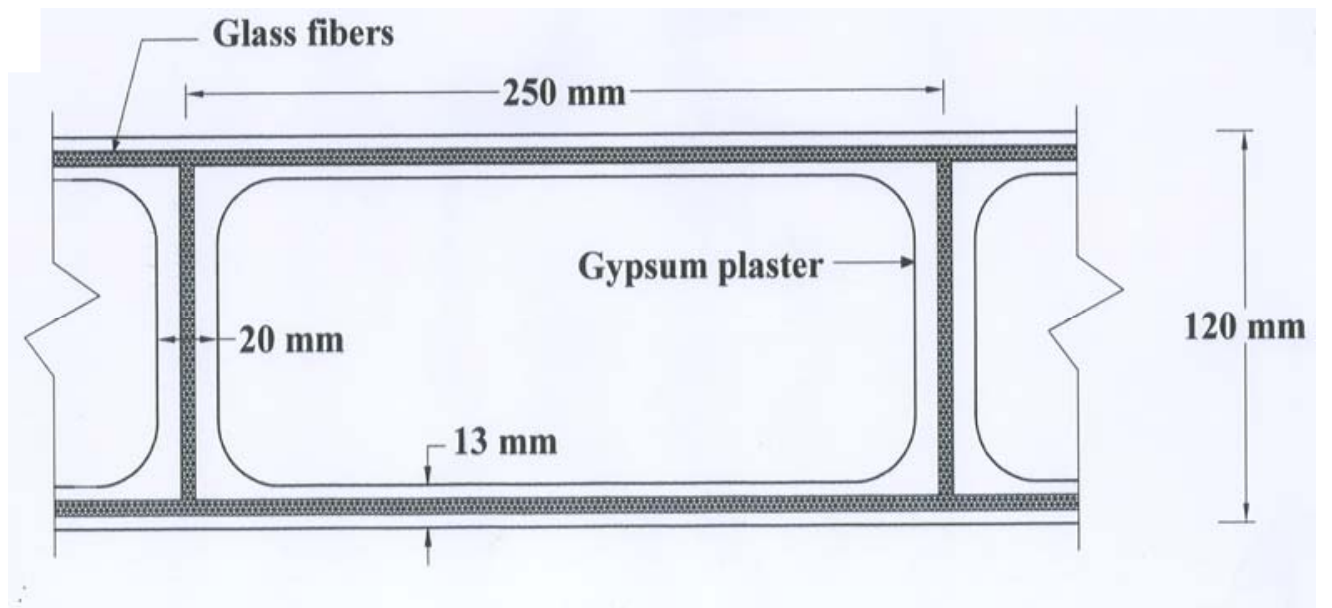

(b)

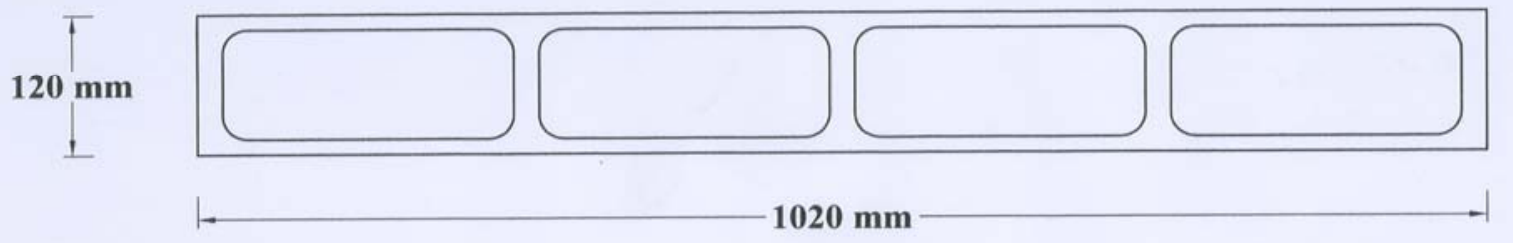

Fig. 1 Cross section of GFRG wall panel (a) Details of one cell, (b) Panel of $1.02 \mathrm{~m}$ 


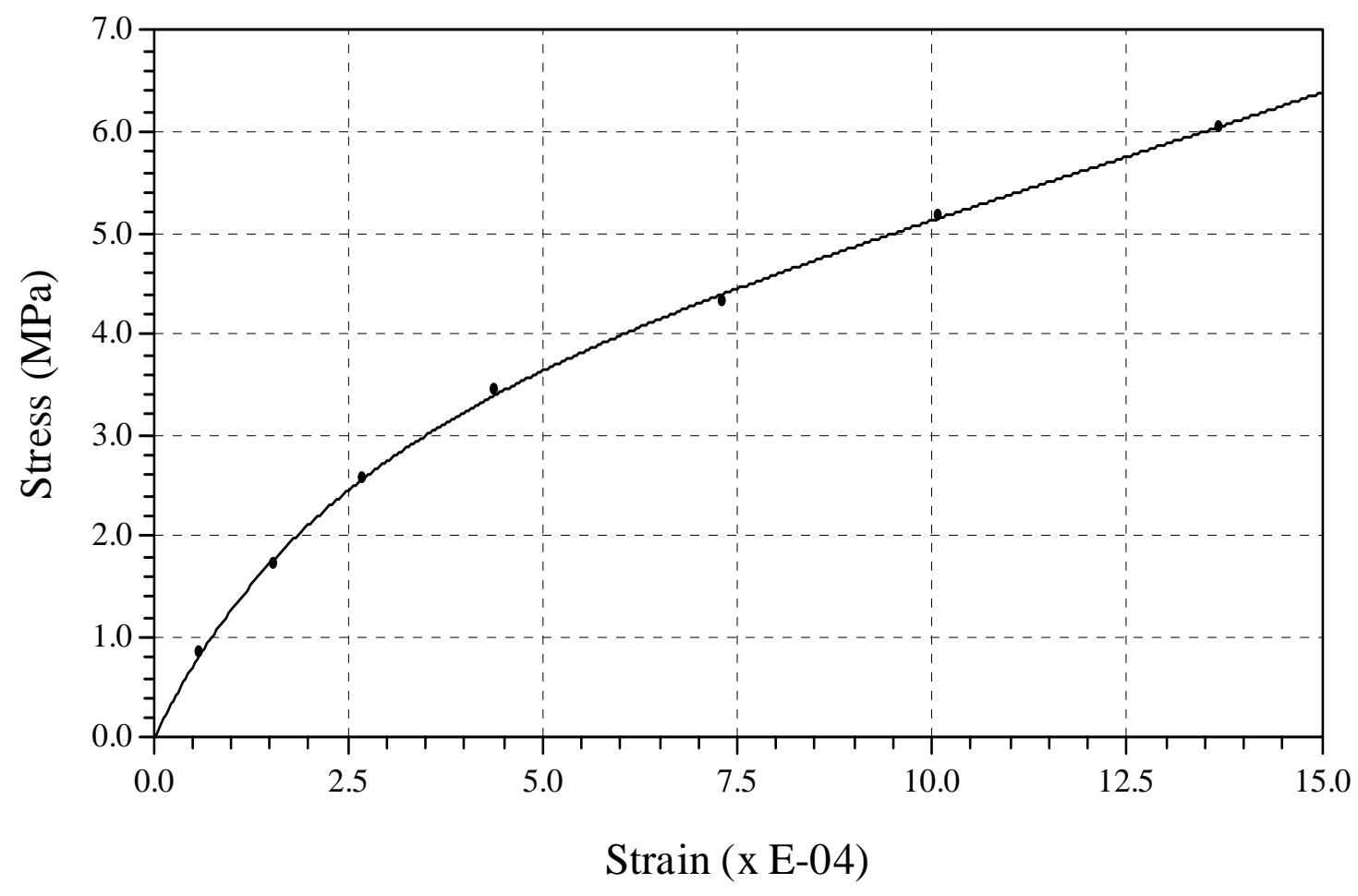

Fig. 2 Stress-Strain curve of GFRG 


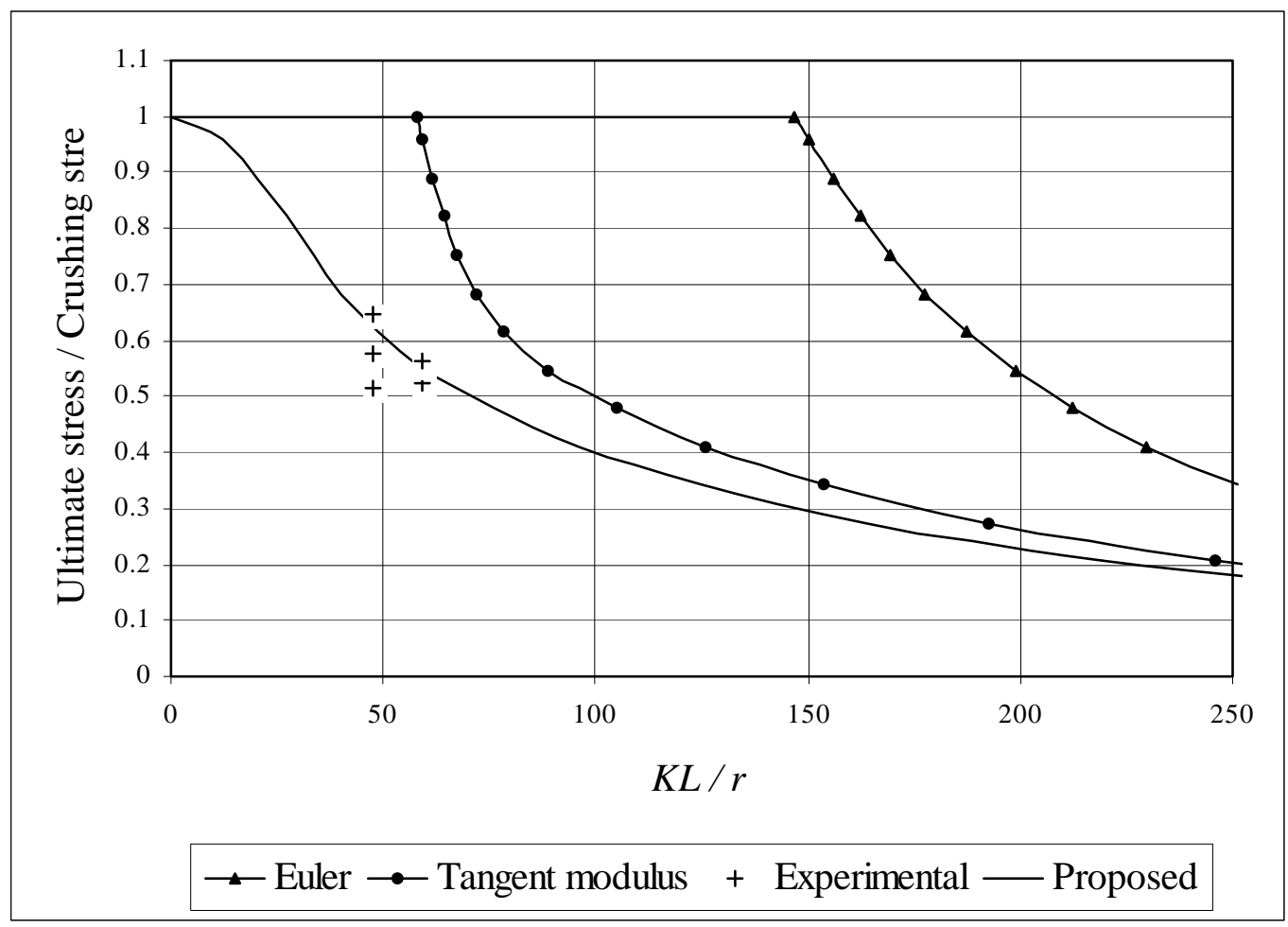

Fig. 3 Comparison of various methods with experimental values 


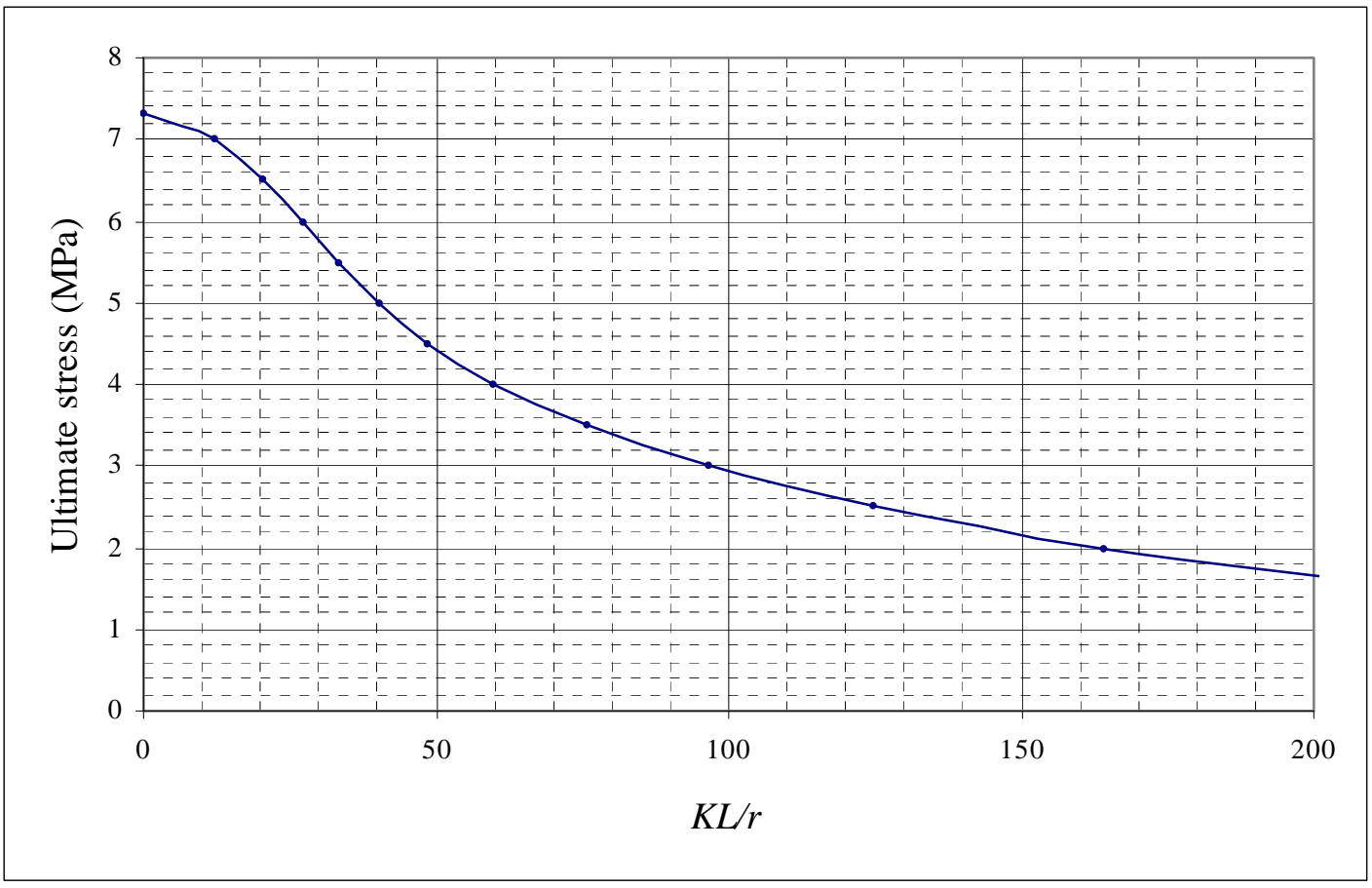

Fig. 4 Relationship between critical stress and slenderness ratio by proposed method for unfilled GFRG walls 
Table 1. Tangent modulus of GFRG

SI.No Stress $(\sigma)$ Tangent modulus( $\left.E_{t}\right)$

(Mpa) (Mpa)

\begin{tabular}{lll}
\hline 1 & 0.0 & $1.60 \times 10^{4}$ \\
2 & 0.5 & $1.36 \times 10^{4}$ \\
3 & 1.0 & $1.12 \times 10^{4}$ \\
4 & 1.5 & $0.92 \times 10^{4}$ \\
5 & 2.0 & $0.75 \times 10^{4}$ \\
6 & 2.5 & $0.60 \times 10^{4}$ \\
7 & 3.0 & $0.48 \times 10^{4}$ \\
8 & 3.5 & $0.39 \times 10^{4}$ \\
9 & 4.0 & $0.32 \times 10^{4}$ \\
10 & 4.5 & $0.28 \times 10^{4}$ \\
11 & 5.0 & $0.26 \times 10^{4}$ \\
12 & 5.5 & $0.251 \times 10^{4}$ \\
13 & 6.0 & $0.25 \times 10^{4}$
\end{tabular}

Note : Intermediate values can be obtained by linear interpolation. 
Table 2. Experimental ultimate loads of both ends pinned panels

\begin{tabular}{|c|c|c|c|c|c|}
\hline \multirow[t]{2}{*}{ SI.No } & \multirow{2}{*}{$\begin{array}{l}\text { Size of panel } \\
L \times B \times T \\
(\mathrm{~mm})\end{array}$} & \multirow{2}{*}{$\begin{array}{l}\text { Ultimate } \\
\text { load } \\
\text { (kN) }\end{array}$} & \multirow{2}{*}{$\begin{array}{l}\text { Ultimate load } \\
\qquad \begin{array}{c}\mathrm{P}_{\mathrm{eu}}^{*} \\
(\mathrm{kN})\end{array}\end{array}$} & \multicolumn{2}{|c|}{ MeanUltimate } \\
\hline & & & & $\begin{array}{l}\text { load } \\
(\mathrm{kN})\end{array}$ & $\begin{array}{r}\text { stress }\left(\sigma_{\mathrm{eu}}\right) \\
(\mathrm{MPa})\end{array}$ \\
\hline 1 & $2850 \times 1020 \times 120$ & $135^{\mathrm{a}}$ & 135 & & \\
\hline 2 & $2850 \times 2000 \times 120$ & $270^{\mathrm{b}}$ & 138 & & \\
\hline 3 & $2850 \times 2000 \times 120$ & $285^{b}$ & 145 & 141.5 & 4.0 \\
\hline 4 & $2850 \times 2000 \times 120$ & $290^{b}$ & 148 & & \\
\hline
\end{tabular}


Table 3. Experimental ultimate loads of one end fixed and other end pinned panels[5].

\begin{tabular}{llccc} 
SI.No & Size of panel & Ultimate load & Mean $P_{\text {eu }}$ & Ultimate stress $\left(\sigma_{\text {eu }}\right)$ \\
& $L \times B \times T(m)$ & $(k N)$ & $(k N)$ & $(k N)$ \\
\hline 1 & $2850 \times 1020 \times 120$ & 170 & & \\
2 & $2850 \times 1020 \times 120$ & 151 & 152.0 & 4.23 \\
3 & $2850 \times 1020 \times 120$ & 135 & & \\
\hline
\end{tabular}


Proceedings of the 7hㅡ ICCAE Conf. 27 -29 May, 2008

Table 4. Compressive strength of GFRG blocks

\begin{tabular}{llc} 
SI.No & Crushing & Average crushing \\
& $\begin{array}{l}\text { Stress } \\
(\mathrm{MPa})\end{array}$ & $\begin{array}{c}\text { Stress }\left(\sigma_{\mathrm{c}}\right) \\
(\mathrm{MPa})\end{array}$ \\
\hline 1 & 7.10 & \\
2 & 7.28 & 7.31 \\
3 & 7.55 & \\
\hline
\end{tabular}


Proceedings of the 7hㅡ ICCAE Conf. 27 -29 May, 2008

Table 5. Recommended values of effective length factors[2]

\begin{tabular}{lll} 
Sl. No & End supports & $\mathrm{K}$ \\
\hline 1 & Both ends pinned & 1.00 \\
2 & One end pinned and & \\
& other end fixed & 0.80 \\
3 & Both ends fixed & 0.65 \\
\hline
\end{tabular}


Proceedings of the 7hㅡ ICCAE Conf. 27 -29 May, 2008

Table 6. Comparison of theoretical estimate of failure loads of unfilled GFRG wall panels with experimental results

\begin{tabular}{llcc}
\hline SI.No & \multicolumn{2}{c}{ Method } & \multicolumn{2}{c}{ Failure loads } \\
& & $\begin{array}{c}\text { Both ends pinned } \\
(\mathrm{kN})\end{array}$ & One end fixed other end pinned \\
& & 1618 & 2527 \\
\hline 1 & Eulers theory & 253 & 263 \\
2 & Tangent modulus theory & 144 & 164 \\
3 & Proposed method & 135 to 148 & 135 to 170 \\
4 & Experimental results & & \\
\hline
\end{tabular}

